\title{
Inclusion Removal in Molten Magnesium by Pulsed Electric Current
}

\author{
Guozhu ZHANG, Longge YAN and Xinfang ZHANG*
}

State Key Laboratory of Advanced Metallurgy, School of Metallurgical and Ecological Engineering, University of Science and Technology Beijing, Beijing, 100083 P.R. China.

(Received on August 3, 2019; accepted on November 5, 2019)

\begin{abstract}
The effect of pulsed electric current on the removal of $\mathrm{MgO}$ inclusions, which deteriorate mechanical and corrosion properties of magnesium alloys, was investigated. Through characterizing the number and size distribution of $\mathrm{MgO}$ inclusions, it's found that the $\mathrm{MgO}$ inclusions were expelled to the surface (bottom and top) of the magnesium alloy melt and then absorbed by the coating agent, treated by the electropulsing. Besides, the electropulsing also promoted the aggregation of the inclusions, but the large size inclusion only exists on the surface of the sample. Based on the differences in electrical properties between the inclusions and the magnesium alloy melt, a force from electric current to electrically neutral $\mathrm{MgO}$ inclusion has been identified to drive the particles' movement. Further, the results of numerical calculation show that under the action of pulse current, the migration of inclusions to the surface can reduce the system free energy, and the aggregation tendency between two inclusions with a relatively large radius is significantly stronger than the two inclusions with a smaller radius. The excellent agreement between numerical calculations and experimental data demonstrates that employing the electropulsing to separate the particles from the liquids is a fantastic new method in metal melt purification.
\end{abstract}

KEY WORDS: magnesium alloy; pulsed electric current; MgO inclusions; purification.

\section{Introduction}

The magnesium alloys, as the lightest metal structural material, exhibit good damping capacity, high impact resistance, a high strength to weight ratio and easy to process and recycle, ${ }^{1-3)}$ which is widely used in aerospace, automotive, electronic communications. ${ }^{4)}$ Despite these advantages, they exhibit lower ultimate tensile strength and yield strength, as well as lower elastic modulus, and poorer corrosion resistance, ${ }^{5-7)}$ while inclusions in magnesium alloys have an important influence on these properties. For magnesium alloys with inclusions and shrinkage porosities, fatigue cracks will preferentially initiate at these defects, resulting in the remarkable reduction of fatigue lifetimes and the subsequent decrease of fatigue strengths, especially at high numbers of cycles. ${ }^{8-10)}$ The in-situ tensile test determines the microscopic failure mode of high pressure die-cast AZ91HP magnesium alloy and the microstructure analysis confirms the interaction of pores and inclusions during material failure. ${ }^{11)}$ The results indicate that with decreasing significantly the number and size grade of inclusions for the alloy refined with JDMJ flux, tensile strength and elongation increase. ${ }^{12)}$ In the study of the long-term oxide growth kinetics of pure magnesium and several magnesium alloys under atmospheric conditions, the phenomenon of local oxidation of iron or manganese inclusions was observed from second-

\footnotetext{
* Corresponding author: E-mail: xfzhang@ustb.edu.cn DOI: https://doi.org/10.2355/isijinternational.ISIJINT-2019-485
}

ary ion mass spectrometry images near the surface region. The oxidation rate of samples increased significantly after exposure for a few hours. ${ }^{13)}$ In addition, the as-extruded alloy with lower impurity content is found to possess obviously higher damping capacity in the relatively high strain region than that with higher impurity concentration. ${ }^{14)}$ In particular, Fe element, even at small amounts, can severely deteriorate the corrosion resistance of magnesium alloys. If magnesium and magnesium alloys are contaminated with $\mathrm{Fe}$ impurities above $40 \mathrm{ppm}$, the corrosion rates usually exceed $20 \mathrm{~mm} / \mathrm{y} .{ }^{15-17)}$ The melt purification of magnesium alloys has become an important way to improve the properties of magnesium alloys.

With respect to the purification of magnesium alloys, adding fluxes to the melt during the melting process is the most commonly method. ${ }^{18)}$ Although fluxes can remove non-metallic inclusions from melts of magnesium alloys, their effectiveness at decreasing the impurity elements of magnesium melts is not very satisfying. ${ }^{19,20)}$ What is more, using fluxes may result in loss of alloying elements from the melt and secondary pollution through bringing in some nonmetallic impurity elements like $\mathrm{F}$ and $\mathrm{Cl}^{21,22)}$ In order to improve the purification effect, the magnesium alloy melt filtration purification technology was developed. Using the foam ceramic filter to decrease the amount of inclusions in the AZ91 alloy was proved to be good filtration efficiency and can remove small inclusions of 10-20 $\mu \mathrm{m}$. But this method is costly. ${ }^{23,24)}$ Further, based on low-temperature melt treatment without adding any flux, a new low-cost melt 
purification method for magnesium alloys, namely melt selfpurification technology, was developed. ${ }^{25)}$ The combination of co-solvent and rotary bubble agitation improves the melt quality, and decreases the volume fraction of inclusions from $0.47 \%$ to $0.28 \%$ compared to the initial alloy. ${ }^{26)}$ In addition, centrifugal separation and precipitation techniques can be used to deposit inclusions at the bottom of the crucible, which can also play a purification role, but it is difficult to remove nitrides and oxides. ${ }^{27,28)}$ These methods have played an important role in the purification of magnesium melt, but they all have some limitations, such as high cost, low purification efficiency and selectivity for the type and size of inclusions. In view of these limitations, an attempt was made to explore a new method of purifying magnesium alloys, namely melt purification under electrical pulses.

In the previous research for steel purification, based on the differences in electrical properties between the inclusions and liquid metal, the motion of inclusion particles in molten steel under the action of current was creatively studied. ${ }^{29,30)}$ It is found that the particle was expelled towards the surface of the matrix and the electropulsing technique can separate inclusion particles ( $>2 \mu \mathrm{m}$ ) from the liquid. In addition, Zhao and Qin $^{31)}$ further studied the relative motion, interaction mode and configuration evolution of multiple inclusions under current processing, which indicated that the pulsed electric current has agglomeration and deformation effects on the inclusions under specific conditions. Yang ${ }^{32)}$ applied a current pulse between the immersion nozzle and the plug, which found that the inner wall became smooth and the thickness of the adherent inclusions was reduced by about $50 \%$ during continuous casting.

Based on the difference of electrical properties between $\mathrm{MgO}$ inclusions and liquid metals, the effects of electrical pulse on the number and distribution of inclusions were quantitatively analyzed by microscopic photographs combined with quantitative image analysis and numerical calculation methods. The feasibility of removing $\mathrm{MgO}$ inclusions and its mechanism of action were investigated.

\section{Experimental Procedures}

A commercial AZ31 (Mg-3.0Al-1.0Zn in wt.\%) magnesium alloy was used in this study. The investigated materials (magnesium alloy, covering agent) and the used tools were dried in the drying oven at $200^{\circ} \mathrm{C}$ over $2 \mathrm{~h}$. The magnesium alloy and covering agent were put into a corundum crucible $30 \mathrm{~mm}$ in diameter and $70 \mathrm{~mm}$ in height, and the corundum crucible was put in a well-type resistance furnace of $300^{\circ} \mathrm{C}$, then heated to $720^{\circ} \mathrm{C}$. Applying an electrical pulse after the magnesium alloy is completely melted (the electrode gap was about $10 \mathrm{~mm}$ ). The parameters of the electropulsing applied are listed in Table $\mathbf{1}$ and the experimental configuration is given in Fig. 1. The solidified sample was sectioned and marked along the current direction. Then the sectioned samples were grinded and roughly polished through successively finer grits of diamond slurry. The next fine polishing was performed using colloidal silica slurry containing 0.04 $\mu \mathrm{m}$ silica particles. The polished samples were etched in a solution (5 $\mathrm{ml}$ acetic acid, $6 \mathrm{~g}$ picric acid, $10 \mathrm{ml} \mathrm{H}_{2} \mathrm{O}$, and $100 \mathrm{ml}$ ethanol) for $10 \mathrm{~s}$, rinsed clean with alcohol and examined with metallographic microscope, scanning
Table 1. Pulse processing parameters for the investigated samples.

\begin{tabular}{ccccc}
\hline \multirow{2}{*}{$\begin{array}{c}\text { Frequency } \\
(\mathrm{Hz})\end{array}$} & $\begin{array}{c}\text { Width } \\
(\mu \mathrm{s})\end{array}$ & $\begin{array}{c}\text { Current density } \\
\left(\mathrm{A} / \mathrm{m}^{2}\right)\end{array}$ & \multicolumn{2}{c}{ Action time $(\mathrm{s})$} \\
\cline { 4 - 5 } & & & In melt & In solidification \\
\hline 1 & 60 & $4.1 \times 10^{5}$ & 1200 & 1200 \\
50 & 60 & $4.1 \times 10^{5}$ & 1200 & 1200 \\
100 & 60 & $4.1 \times 10^{5}$ & 1200 & 1200 \\
\hline
\end{tabular}

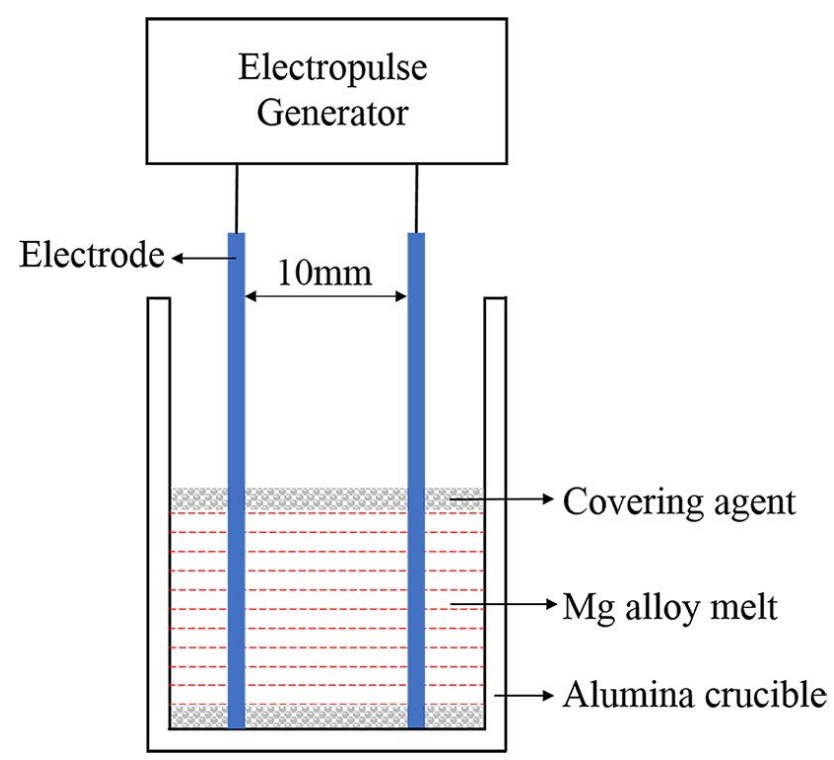

Fig. 1. Experimental setup for pulsed electric current treatments (Online version in color.)

electron microscopy (SEM) and energy dispersive X-ray spectrometer (EDS). The observations for metallographic samples were conducted by SEM at $20 \mathrm{kV}$ and the chemical compositions of the inclusions were analyzed by EDS.

The software Image $\mathrm{J}$ was used to analyze the evolution of inclusion size and distribution by statistics of SEM images at different locations of the investigated samples. MATLAB was used to calculate the free energy change of inclusions during electric pulse treatment, and then the motion behavior of inclusions with different radius under pulse current was calculated. In the calculation process, the required sample size is $30 \mathrm{~mm} \times 30 \mathrm{~mm} \times 2 \mathrm{~mm}$, the current density is $4.1 \times 10^{5} \mathrm{~A} / \mathrm{m}^{2}$, the shape of the inclusion is equal to the sphere, and the distance between the inclusions is the center of the sphere.

\section{Results and Discussion}

Due to the active chemical properties of magnesium, giving: ${ }^{33)}$

$$
2 \mathrm{Mg}+\mathrm{O}_{2}=2 \mathrm{MgO}
$$

The affinity between $\mathrm{Mg}$ and $\mathrm{O}$ is high, especially at high temperature. In addition, magnesium can react with water in both solid and liquid state. The reaction occurred as follows:

$$
\begin{aligned}
\mathrm{Mg}+\mathrm{H}_{2} \mathrm{O} & =\mathrm{MgO}+\mathrm{H}_{2} \uparrow, \ldots \ldots . \\
\mathrm{MgO}+2 \mathrm{H}_{2} \mathrm{O} & =\mathrm{Mg}(\mathrm{OH})_{2}+\mathrm{H}_{2} \uparrow,
\end{aligned}
$$


Those reactions are more intense than that of oxygen under the same conditions. The inclusions in magnesium alloy are mainly $\mathrm{MgO}$, and its melting point is as high as $2852^{\circ} \mathrm{C}$, which cannot be melted during the melting process. The density of $\mathrm{MgO}$ inclusion is about twice as much as the magnesium melt, and it has a tendency to subside in the magnesium alloy melt. In addition, $\mathrm{MgO}$ inclusion has a different thermal expansion coefficient from the matrix, and forms a void around the inclusions due to the different shrinkage speeds during rapid cooling, forming a source of thermal fatigue cracks. ${ }^{34)}$ Therefore, the presence of $\mathrm{MgO}$ inclusions leads to more defects during processing.

The three forms and distribution of $\mathrm{MgO}$ inclusions in AZ31 magnesium alloy were identified by SEM, as shown in Fig. 2. It can be seen that $\mathrm{MgO}$ inclusions exists in both grain and grain boundaries. There are three types, including granular, lamellar, and cluster, whose location are slightly different. The lamellar and large granules are mainly distributed near the grain boundary, while the small size granular $\mathrm{MgO}$ inclusions and the clustered $\mathrm{MgO}$ inclusions are mainly in the interior. Granular and clustered $\mathrm{MgO}$ inclusions and $\beta$ phase coexist in matrix, $\mathrm{MgO}$ inclusion is attached to $\beta$ phase, and the white part of this picture is $\beta$ phase.

Figure 3 shows the number of $\mathrm{MgO}$ inclusions per unit area at different locations before and after electric pulse treatment. It can be seen that the distribution of the number of $\mathrm{MgO}$ inclusions had changed significantly by the electropulsing treatment. In the untreated samples, $\mathrm{MgO}$ inclusion is almost evenly distributed in the sample, the amount of $\mathrm{MgO}$ inclusions at the bottom is slightly more than that at the top, but not obvious. Treated by the electropulsing of different frequencies, the number of inclusions per unit area in the sample decreases significantly in the middle, while the inclusions at the bottom and the top were slightly increased. At the same time, comparing the results of three different frequencies electric pulse treatment, it is not difficult to find that the $50 \mathrm{~Hz}$ electric pulse processing is the best.

In order to display the quantitative distribution and morphology of $\mathrm{MgO}$ inclusions more intuitively, the microstructure of different parts of the tested samples were examined, as shown in Fig. 4. Morphologically, the inclusions before and after the pulse treatment have the same morphology, most of them are in the form shown in Figs. 2(b), 2(c). The horizontal direction of the figure is the top, middle and bottom of the sample, respectively, and the longitudinal direction is the samples of different treatment methods. The number in the upper right corner of each image shows the number of $\mathrm{MgO}$ inclusions in the image. Horizontally, the number of inclusions at different parts is significantly different for the same sample, and the middle part is significantly less than the top and bottom ((b) < (a) (c), (e) < (d) (f), (h) $<$ (g) (i), (k) < (j) (l)). Longitudinally, for the same part, treated by the electropulsing, the number of $\mathrm{MgO}$ inclusions at the tops increased, the number of $\mathrm{MgO}$ inclusions at the middle part decreased significantly, and the number of $\mathrm{MgO}$ inclusions at the bottoms increased obviously. Simultaneously, the change was the most significant treated by an electric pulse of $50 \mathrm{~Hz}$. Further, there are relatively large $\mathrm{MgO}$ inclusions at the bottom and top. The results of this part are consistent with the statistical results shown in Fig. 3.

The number and particle size distribution of $\mathrm{MgO}$ inclusion in the sample are displayed in Fig. 5. Figure 5(a) cor-

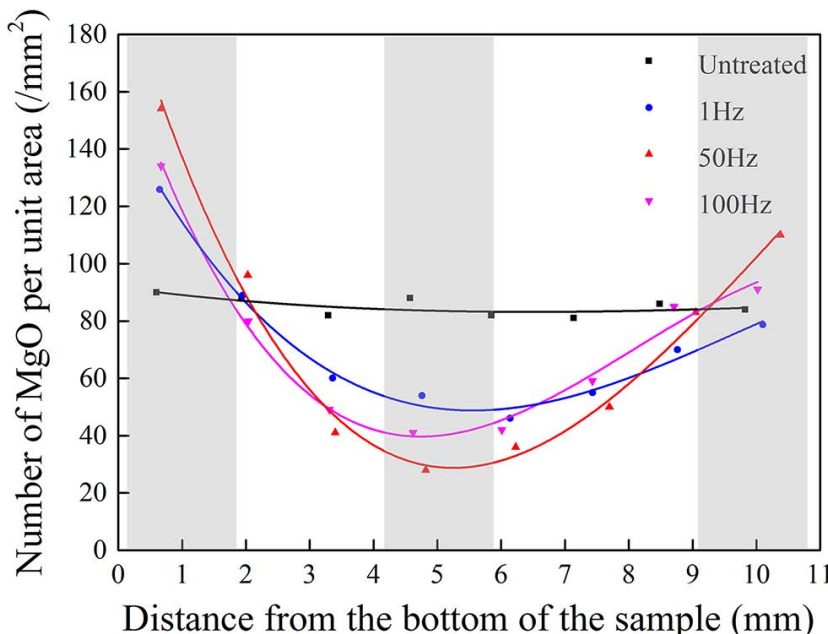

Fig. 3. Variation of $\mathrm{MgO}$ inclusion number per unit area in samples before and after electric pulse treatment. (Online version in color.)

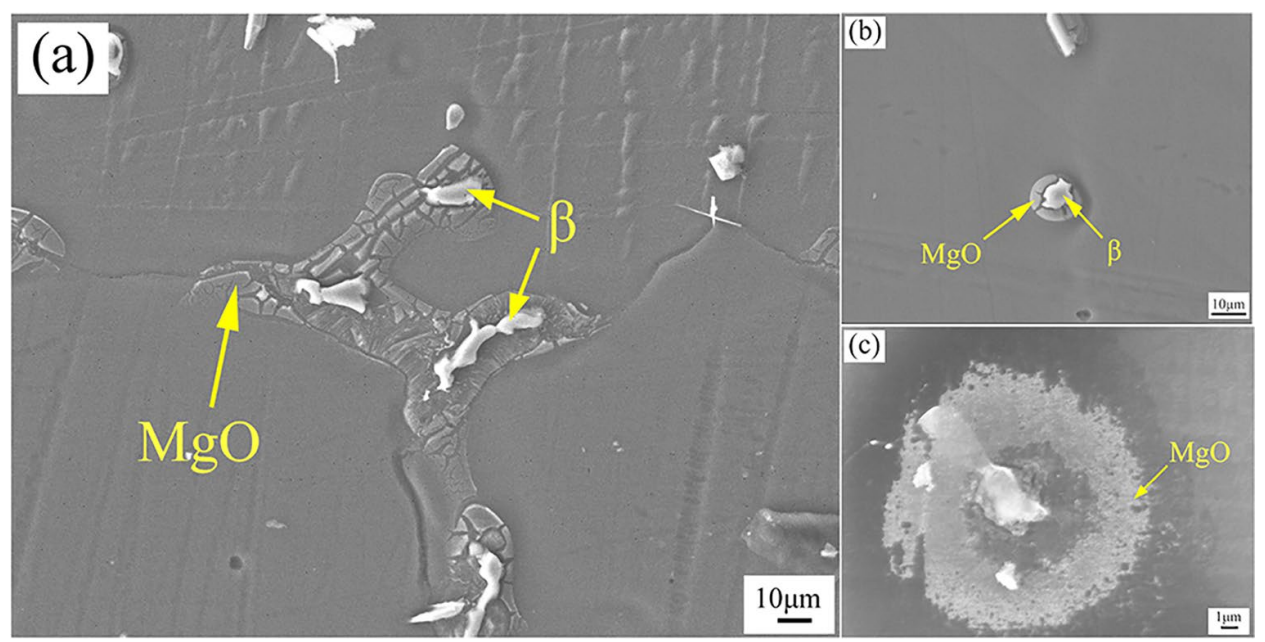

Fig. 2. SEM images showing the microstructure of $\mathrm{MgO}$ inclusions in $\mathrm{AZ} 31$ magnesium alloy: (a) Lamellar $\mathrm{MgO}$ inclusion; (b) Granular $\mathrm{MgO}$ inclusion; (c) Cluster $\mathrm{MgO}$ inclusion. (Online version in color.) 


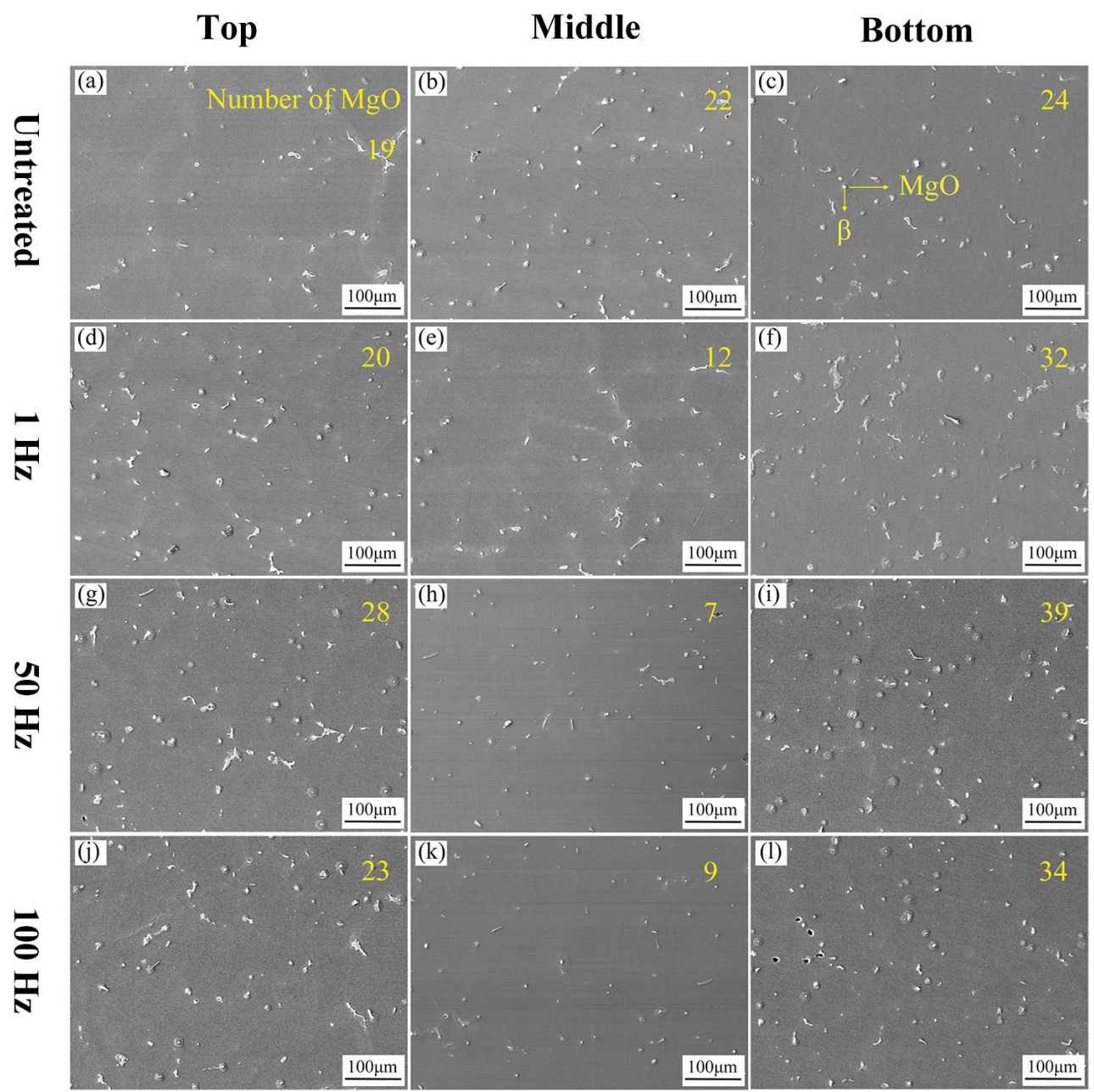

Fig. 4. SEM images of typical parts of the sample before and after electric pulse treatment. (Online version in color.)
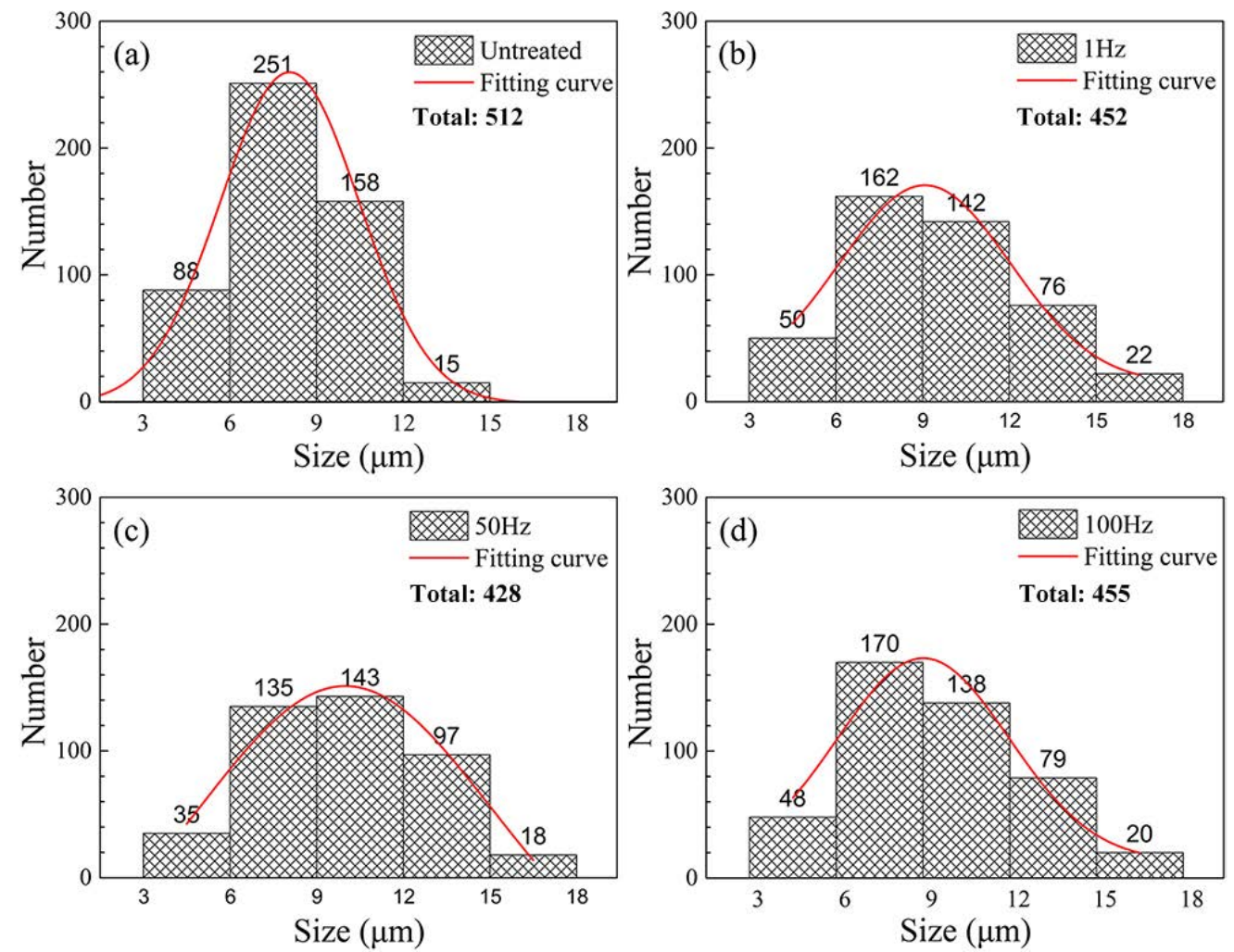

Fig. 5. Number and size distribution of $\mathrm{MgO}$ inclusions in samples before and after electric pulse treatment: (a) Without electric current treatment; (b, c, d) Electric current treatment with different frequencies. (Online version in color.) 
responds to the sample without electric pulse treatment. It is found that the size ranges from 3 to $15 \mu \mathrm{m}$, mainly within 6 to $9 \mu \mathrm{m}$, and the total amount of inclusions is 512 . Figures 5(b), 5(c), 5(d) shows the number and size distribution of inclusions after electric pulse treatment at $1 \mathrm{~Hz}, 50 \mathrm{~Hz}$ and $100 \mathrm{~Hz}$, respectively. It can be seen that the size is in range from 3 to $18 \mu \mathrm{m}$, and large size inclusions range from 15 to $18 \mu \mathrm{m}$ appear, the number of inclusions is 452,428 and 455 , respectively. Compared with that before pulse treatment, the number of inclusions decreases after pulse treatment, but the size of some inclusions increases. Therefore, the whereabouts of the inclusions and the reasons why the size of the inclusions become larger and becomes larger are all to be solved below.

To determine whether the reduced $\mathrm{MgO}$ inclusions have entered the slag, the composition of the slag before and after the electric pulse treatment was analyzed. The XRD patterns

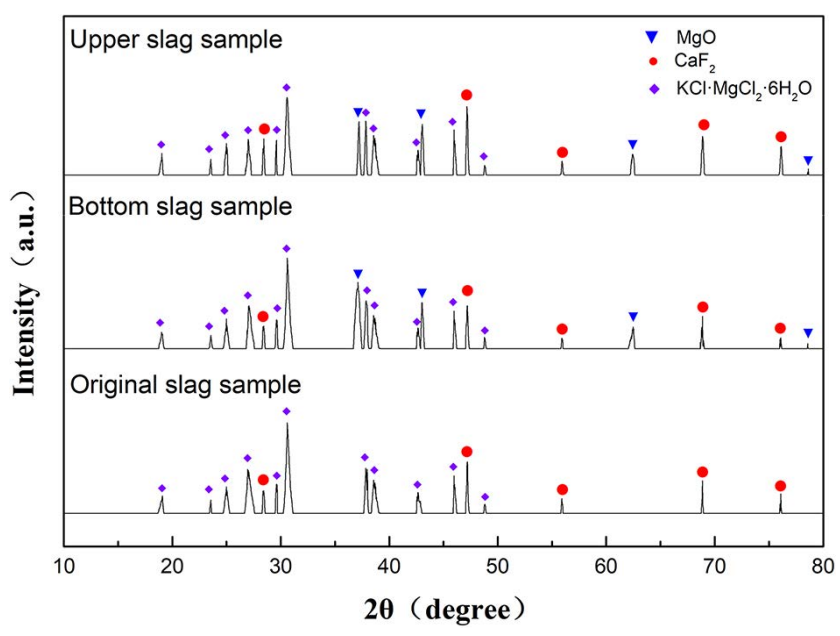

Fig. 6. The XRD patterns of slag before and after electric pulse treatment. (Online version in color.)
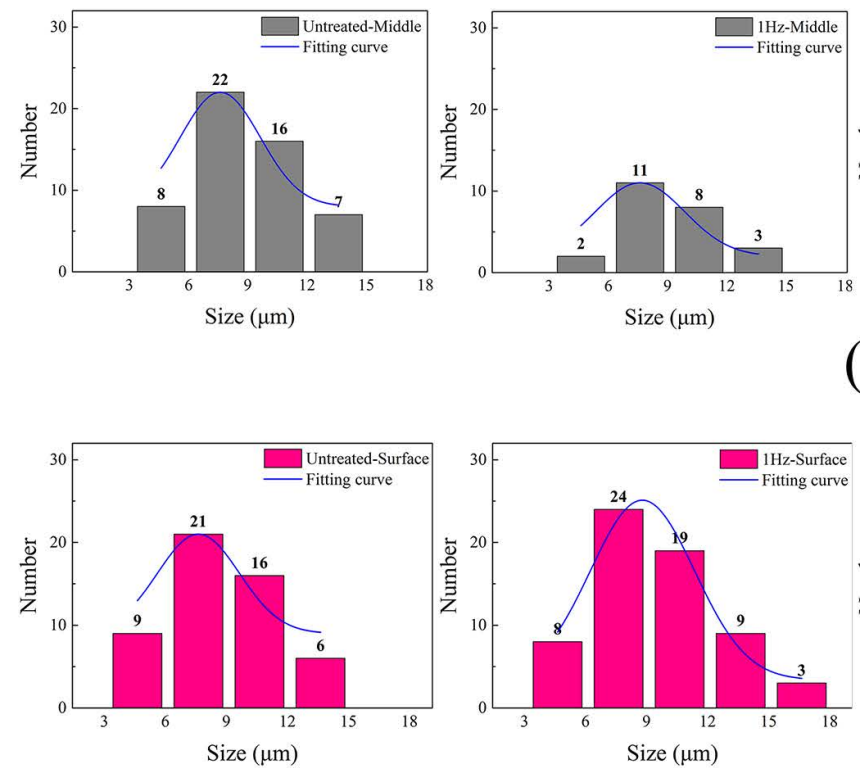

(b)
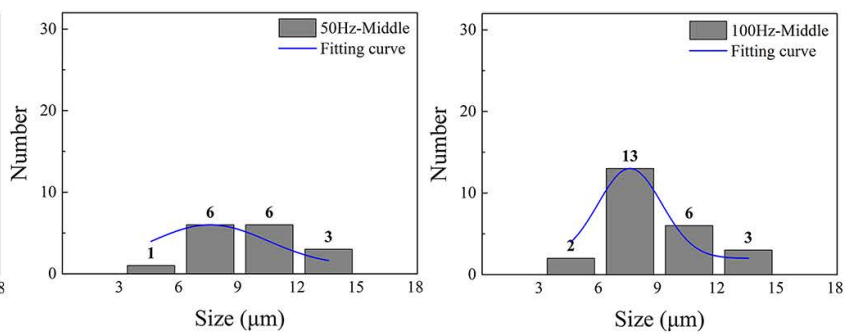

(a)
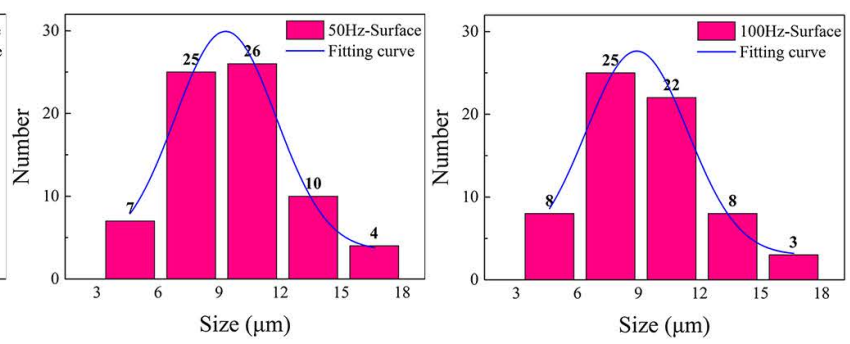

of slag before and after electric pulse treatment is shown in Fig. 6. It should be noted that $\mathrm{MgO}$ inclusion was present in the slag after the pulse current treatment, but no $\mathrm{MgO}$ inclusion was found in the original slag. It was demonstrated that some $\mathrm{MgO}$ inclusions in the magnesium melt were removed from the melt to the slag. The reason why the increased inclusions at the bottom is significantly greater than that at the top is further explained by this result. In all, inclusions are repelled by current to the surface of the melt.

It has been confirmed that the number of inclusions decreases and the size of some inclusions increases under the action of electric pulse. Figure 7 shows the size distribution of the $\mathrm{MgO}$ inclusions on the surface and in the middle of the alloy sample before and after electric pulse treatment, which is used to determine the specific distribution of the inclusions with increased size. Figure 7(a) shows the size distribution of the inclusions in the middle of the sample. There is no change in the size of the inclusions before and after the electric pulse treatment, all of which are in range from 3 to $15 \mu \mathrm{m}$, and different samples of each size grade inclusion quantity change law is consistent. However, the number of inclusions in the middle of the sample decreases significantly after electric pulse treatment. Figure 7(b) shows the distribution of inclusions on the surface of the sample. The number of inclusions on the surface of the sample increased after the treatment of electric pulse, and large size inclusions appeared. The particle size was in range from 15 to $18 \mu \mathrm{m}$. In conclusion, under the action of electric pulse, the $\mathrm{MgO}$ inclusion migrates from the middle to the surface, and eventually the inclusions in the middle decrease, the number of surface inclusions increases, and the radius of surface inclusions increases.

Figure 8 schematically shows a change of current distribution vicinity the $\mathrm{MgO}$ inclusions when current passes. Assuming that the shape of $\mathrm{MgO}$ inclusion is approximately spherical, when the current passes through a single $\mathrm{MgO}$

Fig. 7. Particle size distribution of $\mathrm{MgO}$ inclusions on the surface and middle part of the sample before and after electric pulse treatment: (a) The middle part of the sample; (b) The surface part of the sample. (Online version in color.) 


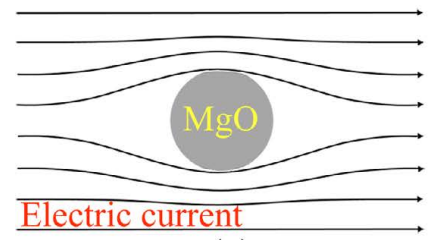

(a)

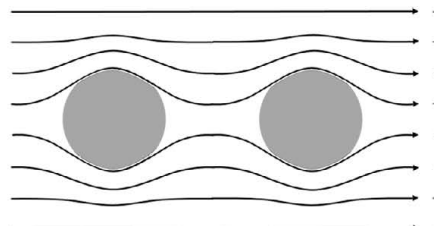

(b)

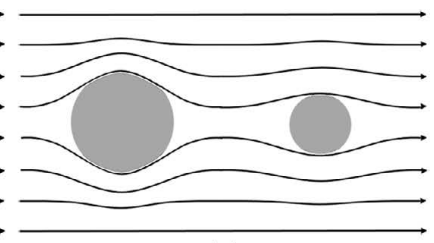

(c)

Fig. 8. Current distribution near $\mathrm{MgO}$ inclusions: (a) current distribution around a single $\mathrm{MgO}$ inclusion; (b) current distribution near two $\mathrm{MgO}$ inclusions with different sizes; (c) current distribution near $\mathrm{MgO}$ inclusions with large difference between two sizes. (Online version in color.)
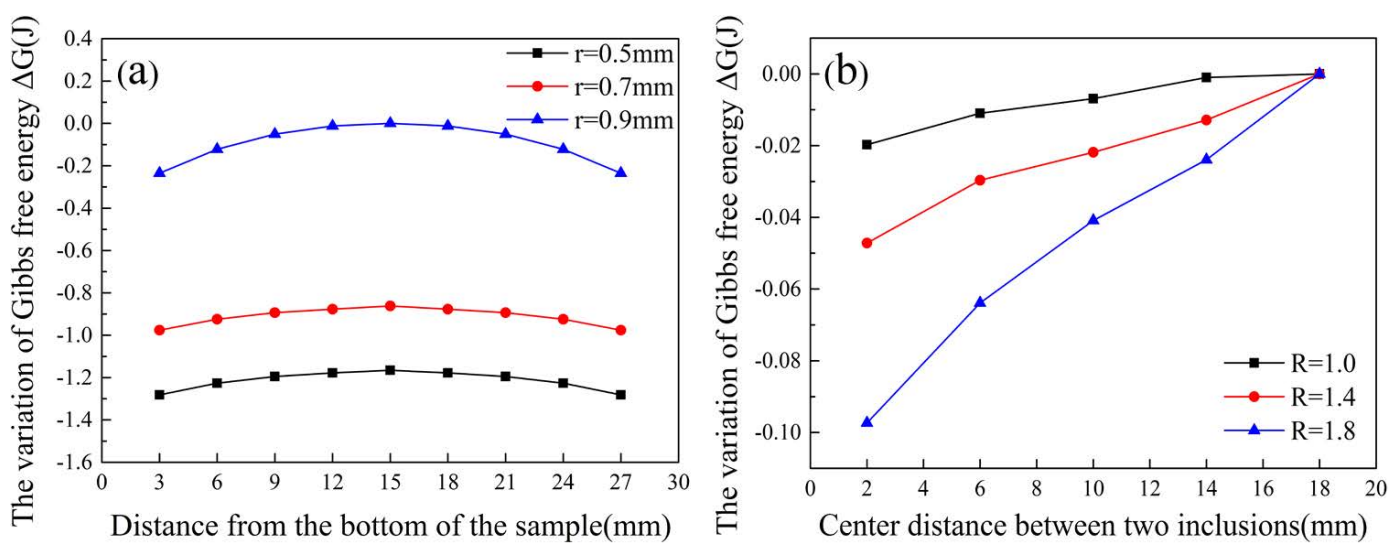

Fig. 9. MATLAB calculations: (a) Gibbs free energy changes at different locations in the electric field for three-size inclusions; (b) Free energy changes of two inclusions with different radius ratios (radius $r_{1}=0.5 \mathrm{~mm}, \mathrm{r}_{2}=0.7$ $\mathrm{mm}$, ratio of $\mathrm{r}_{3}=0.9 \mathrm{~mm}$ to $\mathrm{r}_{0}=0.5 \mathrm{~mm}$, the ratio $\mathrm{R}$ is $1.0,1.4,1.8$ respectively) during electrical pulse processing. (Online version in color.)

inclusion, the current distribution around the $\mathrm{MgO}$ inclusion is shown in Fig. 8(a). Figure 8(b) shows the current distribution around the inclusion after the current passes through two equal-size $\mathrm{MgO}$ inclusions, if the distance between the two inclusions exceeds the critical distance, the current distribution around the two inclusions does not affect each other. It is consistent with the case of a single $\mathrm{MgO}$ inclusion. However, if the spacing of the two inclusions is less than the critical distance, the current distribution around the two inclusions will affect each other. Figure 8(c) shows the current distribution around the $\mathrm{MgO}$ inclusions after the current passes through two $\mathrm{MgO}$ inclusions with large differences in size. In this case, the current distribution around the two inclusions is not uniform, and the influence between them is different. The latter calculations will be discussed in depth. The electrical conductivity of $\mathrm{MgO}$ inclusions at room temperature is $1 \times 10^{-5} \mathrm{~S} / \mathrm{m}$, and that of AZ31 magnesium alloy is $6.28 \times 10^{6} \mathrm{~S} / \mathrm{m}^{35)}$ Although the resistivity of AZ31 magnesium alloy increases by 2 times at melt state, the conductivity of AZ31 magnesium melt is still about $10^{12}$ times larger than that of $\mathrm{MgO}$ inclusion. Therefore, after the pulsed treatment, the current density flowing through the inclusion is much lower than that flowing through the magnesium melt. In order to minimize the system free energy, an inclusion will be expelled to the surface of the molten magnesium alloy by electropulsing.

When a current is applied to a system, the change of total free energy $\Delta G$ is composed of the change of chemical free energy $\Delta G_{\text {chem }}$, the change of surface free energy $\Delta G_{\text {int }}$ and the change of free energy $\Delta G_{\text {elec }}$ caused by pulsed current, as shown in Eq. (4).

$$
\Delta G=\Delta G_{\text {chem }}+\Delta G_{\text {int }}+\Delta G_{\text {elec }}
$$

$\Delta G_{\text {chem }}$ and $\Delta G_{\text {int }}$ did not change substantially when the inclusions were moving in the melt, the current density distribution caused by the inclusions motion would result in changes of $\Delta G_{\text {elec }}$. When the current passes through the conductor, the free energy $\Delta G_{\text {elec }}{ }^{36,37)}$ is expressed as:

$$
G_{\text {elec }}=-\frac{\mu}{8 \pi} \int \frac{\vec{j}(r) \vec{j}\left(r^{\prime}\right)}{\left|r-r^{\prime}\right|} d r d r^{\prime}
$$

where $\mu$ is the magnetic permeability. $r$ and $r^{\prime}$ are respectively two different positions in magnesium melt. $\vec{j}(r)$ is the current density at position $r$ and $\vec{j}\left(r^{\prime}\right)$ is the current density at position $r^{\prime}$. The distribution of electric current density in magnesium melt is affected by the configuration of electrical conductivity in the materials. Inclusions have different electrical properties from that of the magnesium melt. When an inclusion moves from the inside towards the surface of the melt, the current density distribution changes from $\overrightarrow{j_{1}}(r)$ to $\overrightarrow{j_{2}}(r)$. The associated free energy change $\Delta G_{\text {elec }}$ can be expressed as: ${ }^{: 36,37)}$

$$
G_{\text {elec }}=\frac{\mu}{8 \pi} \iint \frac{\overrightarrow{j_{1}}(r) \overrightarrow{j_{1}}\left(r^{\prime}\right)-\overrightarrow{j_{2}}(r) \overrightarrow{j_{2}}\left(r^{\prime}\right)}{\left|r-r^{\prime}\right|} d^{3} r d^{3} r^{\prime}
$$

It can be seen from Eq. (6) that the farther the inclusion is from the center of the sample, the greater the decrease of free energy of the system. That is to say, under the action of pulse current, the process of the inclusion migration to the surface and the bottom is the process of the decrease of free energy. Therefore, in order to minimize the free energy of 


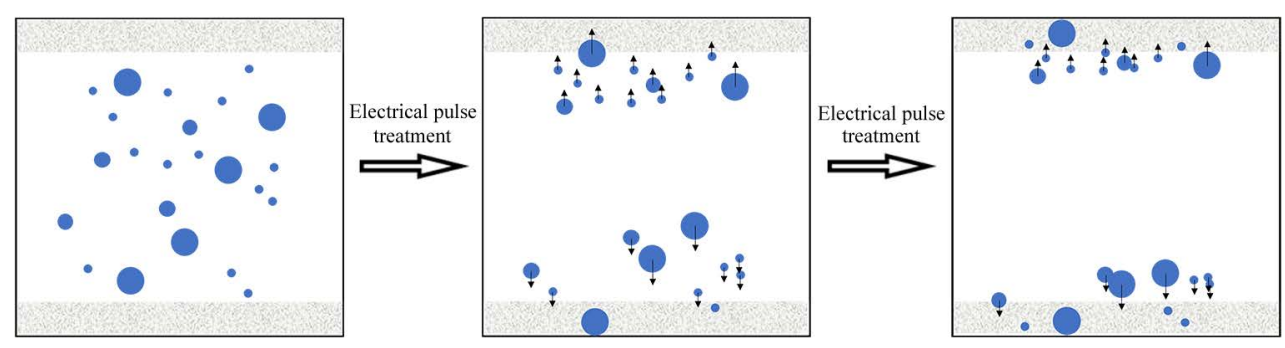

Fig. 10. Schematic diagram of inclusion removal. (Online version in color.)
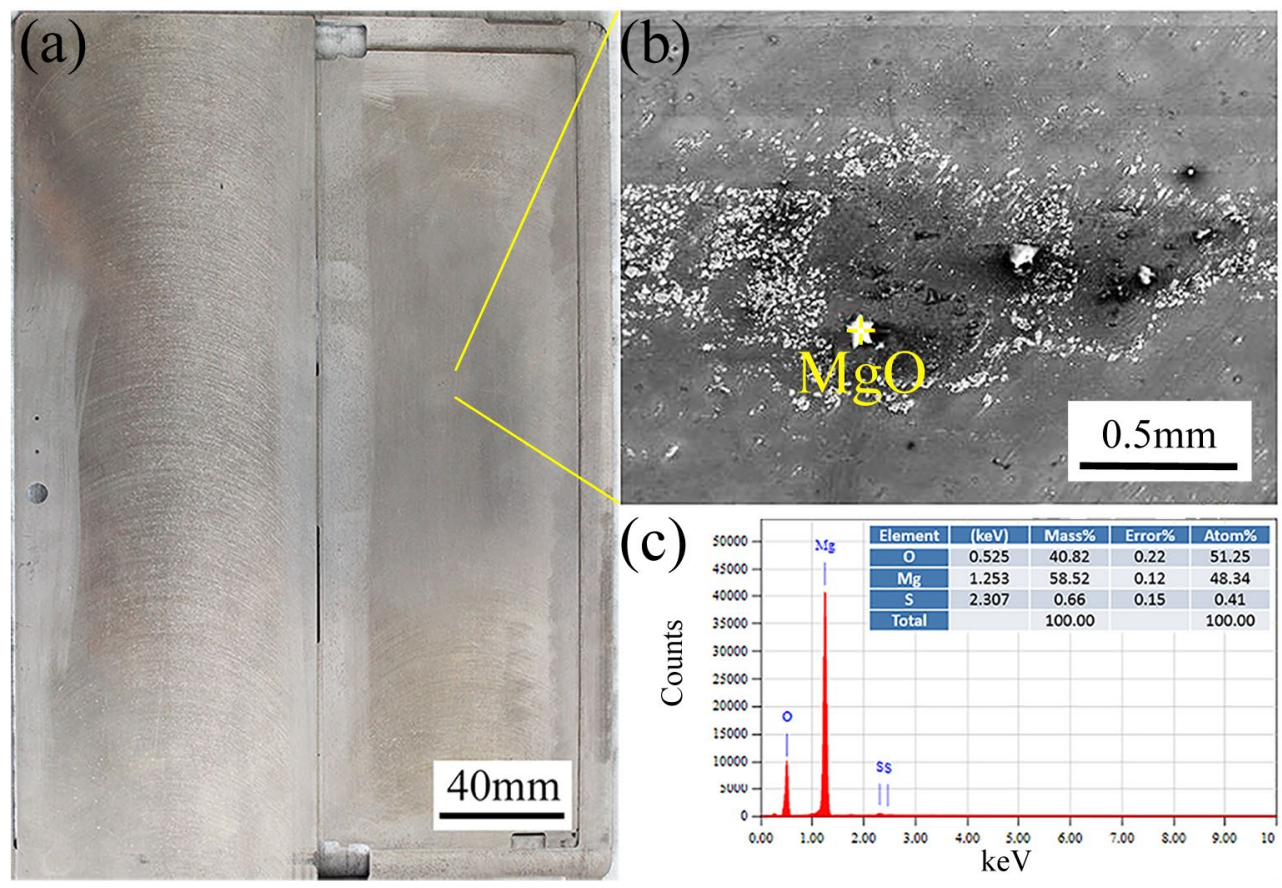

Fig. 11. MgO inclusions in magnesium alloy panels for tablet computers: (a) macro-morphology; (b) micro-morphology; (c) EDS. (Online version in color.)

the system, the inclusions will be removal from the molten magnesium alloy.

Figure 9 shows the calculation results of MATLAB. Figure 9(a) shows the change of Gibbs free energy at different locations in the electric field for three size inclusions. It can be seen that the variation of the free energy of the inclusion particles of the three kind of radius is consistent, and the change of free energy in the intermediate position changes is higher than that in the two ends. In addition, the larger the radius is, the larger the change of free energy is. It can be obtained from the law of free energy change that the farther the corresponding inclusions are from the center of the sample, the greater the reduction of free energy. That is to say, the process of migration of inclusions to the surface and the bottom under the action of the pulse current is a process in which the free energy is lowered. Therefore, the inclusion content gradually increasing from the middle to the both ends appear.

In Fig. 9(b), each line calculates the variation of free energy of two inclusions with different radius ratios during electric pulse treatment. As the distance between the centers of the two inclusions decreases, the change in Gibbs free energy decreases, indicating that the process of inclusions approaching is a process of free energy reduction. When the radius ratio $\mathrm{R}$ is 1.0 , the change of the free energy of the two inclusions is not obvious, indicating that the tendency of the two inclusions to approach is not significant at this time. When the $\mathrm{R}$ is 1.4 , the change of the free energy of the two inclusions increases, the free energy decreases more, and the trend of the inclusions approaching increases. As the $\mathrm{R}$ increases to 1.8 , the free energy changes continue to increase, the free energy decreases more significantly, and the tendency of inclusions to approach is greater. In general, there is a clear tendency to aggregation between large-size inclusions and small-size inclusions under the action of electric pulse.

The removal process of inclusions in magnesium alloy melt is shown in Fig. 10. $\mathrm{MgO}$ inclusion is randomly distributed in untreated samples. After electropulsing treatment, $\mathrm{MgO}$ inclusions move to the top and bottom of the melt from a certain position in the middle, and the distance between inclusions gradually approaches. Accompanied by some inclusions collide or even aggregate with each other, the distance between inclusions continues to narrow. At the same time, the inclusions that reach the melt boundary are driven by eletropulsing and gradually enter the covering agent. Finally, the inclusions are separated from the melt of magnesium alloy. It is precisely that small inclusions are identified as large inclusions in the process of inclusion size statistics because of the collision and aggregation of 
different inclusions. Therefore, the statistical results show that the large size inclusions increase and the small size inclusions decrease.

Separation of inclusions based on the difference in electrical conductivity rather than the density difference between the inclusion and metal melt is a major innovation in this study. Traditionally, the buoyancy caused by the large density difference between inclusions and melts is an important way to achieve purification. However, this pulsed-based separation technique is independent of density and is based on the difference in electrical properties. Moreover, the nonmetallic inclusions generally have an electrical conductivity that is less than the order of the melt, i.e., the use of the difference in electrical properties has less restriction on the separation of inclusions from the metal melt. This provides a possibility to use pulsed current to control the transport of electrically neutral non-metallic inclusions in a conductive liquid, which would be important if the migration facilitates the separation of particles of nearly equal density but the conductivity is quite different. In addition, compared with the traditional purification methods, electropulsing as a transient high-energy input method has the unique technical advantages of high efficiency and low energy consumption in separating particles form metal melt, and has broad application prospects.

$\mathrm{MgO}$ inclusion has a high melting point, which is difficult from that of the melt in the smelting process. The existence of inclusions seriously affects the impact properties, causing impact cracking; even if it does not cause impact cracking, inclusions will lead to poor processing performance and surface finish, and poor corrosion resistance. Figure 11 shows the defects of magnesium alloy panel for tablet computers. The defect is proved to be $\mathrm{MgO}$ inclusion by SEM and EDS. The defect is visible to the naked eye, which seriously affects the surface quality of the product, greatly reduces the qualified rate of the product and leads to increased cost. Therefore, it is meaningful to remove $\mathrm{MgO}$ inclusion in magnesium alloy using electropulsing.

\section{Conclusions}

A new electric pulse purification method was proposed for purifying magnesium alloy melt. The method has the advantages of simple equipment, convenient operation, low energy consumption, safety and high efficiency. The feasibility of using electric pulse treatment to remove $\mathrm{MgO}$ inclusions in magnesium alloys has been proved in this study.

The results show that under the action of pulse current, in order to reduce the free energy of the system, the $\mathrm{MgO}$ inclusions in the melt of magnesium alloy are separated, and the inclusions migrated to the surface are absorbed by the refining agent to achieve the purification effect. In the process of current-driven inclusion movement, some inclusions accumulate and the size of inclusions increases slightly. At the same time, MATLAB calculation shows that the aggregation tendency between the inclusions with larger radius ratio is more obvious. The morphology of inclusions did not change significantly before and after pulse treatment.

\section{Acknowledgements}

The work was financially supported by National Natural Science Foundation of China (U1860206, 51874023, 51601011), Fundamental Research Funds for the Central Universities (FRF-TP-18-003B1), Recruitment Program of Global Experts.

\section{REFERENCES}

1) S. Jayalakshmi, K. C. Guan, K. Joshua and M. Gupta: Adv. Mater. Res., 545 (2012), 247.

2) L. Yang, X. R. Zhou, S. M. Liang, S. F. Rainer, Z. Y. Fan, G. Scamans, J. Robson and G. Thompson: J. Alloy. Compd., 619 (2015), 396.

3) Y. Z. Lü, Q. D. Wang, W. J. Ding, X. Q. Zeng and Y. P. Zhu: Mater. Lett., 44 (2000), 265.

4) B. L. Mordike and T. Ebert: Mater. Sci. Eng. A, 302 (2001), 37.

5) S. H. You, Y. D. Huang, K. U. Kainer and N. Hort: J. Magnes. Alloy., 5 (2017), 239.

6) F. Y. Cao, G. L. Song and A. Atrens: Corros. Sci., 111 (2016), 835.

7) A. Atrens, G. L. Song, M. Liu, Z. M. Shi, F. Y. Cao and M. S. Dargusch: Adv. Eng. Mater., 17 (2015), 400.

8) Y. Kitahara, H. Shimazaki, T. Yabu, H. Noguchi, M. Sakamoto and H. Ueno: Mater. Sci. Forum, 482 (2005), 359.

9) M. F. Horstemeyer, N. Yang, K. Gall, D. L. McDowell, J. Fan and P. M. Gullett: Acta Mater., 52 (2004), 1327.

10) G. Eisenmeier, B. Holzwarth, H. W. Höppel and H. Mughrabi: Mater. Sci. Eng. A, 319-321 (2001), 578.

11) D. G. L. Prakash, D. Regener and W. J. J. Vorster: Mater. Sci. Eng. A, 488 (2008), 303.

12) W. Wang, Y. G. Huang, G. H. Wu, Q. D. Wang, M. Sun and W. J. Ding: J. Alloy. Compd., 480 (2009), 386.

13) N. S. Mcintyre and C. Chen: Corros. Sci., 40 (1998), 1697.

14) X. H. Chen, J. J. Mao, F. S. Pan, J. Peng and J. F. Wang: Trans. Nonferrous Met. Soc. China, 20 (2010), 1305.

15) M. Yang, D. H. Chen, R. Q. Wang and Y. K. Bai: Phys. Lett. A, 379 (2015), 396.

16) M. Liu, P. J. Uggowitzer, A. V. Nagasekhar, P. Schmutz, M. Easton, G. L. Song and A. Atrens: Corros. Sci., 51 (2009), 602.

17) M. Liu, P. J. Uggowitzer, P. Schmutz and A. Atrens: JOM, 60 (2008), 39.

18) T. Hiraki, O. Takeda, K. Nakajima, K. Matsubae, S. Nakamura and T. Nagasaka: Sci. Technol. Adv. Mater., 12 (2011), 035003.

19) S. Guo, J. Zhang, W. Wu and W. Zhou: Prog. Mater. Sci., 97 (2018), 448.

20) J. Kim, H. N. Nguyen, B. S. You and Y. M. Kim: Scr. Mater., 162 (2019), 355.

21) Z. H. Chen: Magnesium Alloy, Chemical Industry Press, Beijing, (2004), 64 (in Chinese).

22) W. Wang, G. H. Wu, Q. D. Wang, Y. G. Huang and W. J. Ding: Mater. Sci. Eng. A, 507 (2009), 207.

23) P. Bakke, T. A. Engh, E. Bathen, D. Øymo and A. Nordmark: Mater. Manuf. Process., 9 (1994), 111.

24) P. Bates and R. A. P. Kent: ISIJ Int., 32 (1992), 682.

25) F. S. Pan, X. H. Chen, T. Yan, T. T. Liu, J. J. Mao, W. Luo, Q. Wang, J. Peng, A. T. Tang and B. Jiang: J. Magnes. Alloy., 4 (2016), 8.

26) J. Mei, W. C. Liu, G. H. Wu, Y. Zhang, Y. T. Zhang, Y. K. Hong, R. X. Zhang, L. Xiao and W. J. Ding: Trans. Nonferr. Met. Soc. China, 25 (2015), 1811.

27) C. J. Simensen: Metall. Trans. B, 12 (1981), 733.

28) Y. H. Yang, B. Song, G. Y. Song, Z. B. Yang and W. B. Xin: Metall. Mater. Trans. B, 47 (2016), 2714.

29) X. F. Zhang and R. S. Qin: Sci. Rep., 5 (2015), 10162

30) X. F. Zhang, W. J. Lu and R. S. Qin: Scr. Mater., 69 (2013), 453.

31) Z. C. Zhao and R. S. Qin: Mater. Sci. Technol., 33 (2017), 1404.

32) X. Yang, Z. Y. Liu and J. K. Yu: J. Mater. Process. Technol., 259 (2018), 341 .

33) F. Czerwinski: JOM, 64 (2012), 1477

$34)$ D. Steiner Petrovič, B. Arh, F. Tehovnik and M. Pirnat: ISIJ Int., 51 (2011), 2069.

$35)$ Z. H. Zhang, F. S. Pan, X. H. Chen and J. Liu: J. Mater. Eng., 1 (2013), 52 (in Chinese).

36) X. L. Wang, J. D. Guo, Y. M. Wang, X. Y. Wu and B. Q. Wang: Appl. Phys. Lett., 89 (2006), 061910.

37) R. S. Qin, E. I. Samuel and A. Bhowmik: J. Mater. Sci., 46 (2011), 2838 . 